\title{
Finite element simulation of low velocity impact loading on a sandwich composite
}

\author{
Vishwas M. ${ }^{1 *}$, Sharnappa Joladarashi ${ }^{1}$ and Satyabodh M. Kulkarni ${ }^{1}$ \\ ${ }^{1}$ Department of Mechanical Engineering, National Institute of Technology Karnataka, Surathkal \\ 575025, Karnataka, India
}

\begin{abstract}
Sandwich structure offer more advantage in bringing flexural stiffness and energy absorption capabilities in the application of automobile and aerospace components. This paper presents comparison study and analysis of two types of composite sandwich structures, one having Jute Epoxy skins with rubber core and the other having Glass Epoxy skins with rubber core subjected to low velocity normal impact loading. The behaviour of sandwich structure with various parameters such as energy absorption, peak load developed, deformation and von Mises stress and strain, are analyzed using commercially available analysis software. The results confirm that sandwich composite with jute epoxy skin absorbs approximately $20 \%$ more energy than glass epoxy skin. The contact force developed in jute epoxy skin is approximately 2.3 times less when compared to glass epoxy skin. von Mises stress developed is less in case of jute epoxy. The sandwich with jute epoxy skin deforms approximately 1.6 times more than that of same geometry of sandwich with glass epoxy skin. Thus exhibiting its elastic nature and making it potential candidate for low velocity impact application.
\end{abstract}

Keywords: Sandwich composite, Jute epoxy, Glass epoxy, Low velocity impact

\section{Introduction}

Composites materials are generally utilized as a part of designing applications, particularly in aeronautics in perspective of their light weight, high strength to weight ratio, stiffness, thermal and corrosion resistance. In any case, outline of composites is a great deal more perplexing contrasted with conventional materials because of their anisotropic behavior. Failure of composites are also complex and can happen because of splitting of fibers being part of whole, part/splitting of matrix, or fiber matrix de bonding or delamination at their interface and may also occur due to various other mechanisms of failure. Hence it needs cautious outline and investigation to be routed to precisely represent basic conduct, particularly when sandwich reaction may fundamentally vary with geometry, material, orientation, stalking sequence or loading condition of composite materials. A computational and demonstrating approach to be utilized for profitable research and plan for composites is particularly fundamental for such investigation by structural designers [1]. Sandwich

\footnotetext{
${ }^{*}$ Corresponding author: vishwasmahesh@gmail.com
} 
structures are being utilized as a part of a few sections of aviation, and marine structures. For the most part these structures are subjected to effects, for example, dropping of the instrument during maintenance, strike due to solid precipitation or bird, and runway debris. Despite the fact that the sheets made of metal has higher strength than FRPs they possess large weight which results in increased cost [2]. Sandwich structures are obtained when two thin skins are appended to a core which is lighter in weight and thicker. These materials have high sp. strength and stiffness against bending [3]. Including transportation vehicles and packaging, sandwich composites are used as a part of basic/semi basic applications. Due to the geometrical advantages provided by sandwiches, they are broadly utilized as vitality retaining frameworks subjected to impact loads. During normal working, sandwich structures may experience low-speed impacts from shots being exceptionally sensible to such loads. In spite of extensive research on sandwich structures, their impact behavior is as yet not completely comprehended [4-5]. Lightweight composite sandwich boards, including fiber strengthened polymer confront sheets and polymeric core, are more generally utilized as a part of vehicles used in defense since their ability to bear the load per unit weight is high and less maintenance. In a few occasions, due to the flying debris, sandwiches may come under the influence of low velocity impact load [6]. PMCs are used widely in sandwiches as they delay the shot as it diminishes its KE [7]. Projectile impact contemplates on PMCs and a sandwich board has predominantly concentrated in the low velocity impact regime in light of its relationship with BVID [8-10]. Based on available literature, it was found that there are no studies available on sandwich composites having composite facings (Jute) with natural rubber core subjected to impact loading under low velocity. The investigations are carried out on impact parameters like Total Energy, contact force, deformation, von Mises stress and strain under low velocity impact condition and how they affect the performance of the components manufactured. The scope of the present work is limited to low velocity impact behavior of sandwich composite using commercially available software. Results pertaining to sandwich with jute epoxy and glass epoxy composite facing with rubber core are compared and an attempt has been made to explore the possibility of using them for low velocity impact applications.

\section{Methodology}

The sandwich model considered for the analysis is shown in fig1. The skin is modeled with a dimension of $150 \mathrm{~mm} \times 150 \mathrm{~mm} \times 6 \mathrm{~mm}$ and core is of thickness $30 \mathrm{~mm}$ which is five times that of skin thickness. Fig 2 shows the meshing of sandwich structure. The auto mesh option is selected to mesh the sandwich and tup. The type of mesh used is Quad with 24,696 nodes and 35,913 elements. The hemispherical tup impactor of radius $6.5 \mathrm{~mm}$ is considered to be made up of steel [11]. The explicit dynamics analysis type is selected to perform the low velocity impact test on sandwich structure. The boundary condition applied for the sandwich structure is fixed support on the edges of the sandwich structure as well as on the four side faces and velocity of $20 \mathrm{~m} / \mathrm{s}$ for the tup. The sandwich structure is defined as flexible material and tup as rigid material. Table 1 gives the properties of materials: glass epoxy and jute epoxy used during analysis [11-15] 


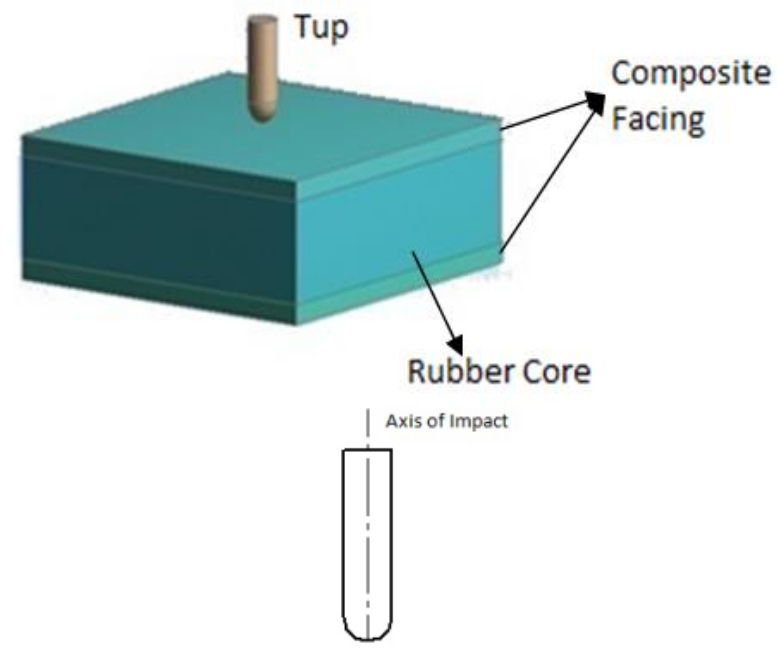

Fig. 1. Sandwich Composite subjected to Normal Impact

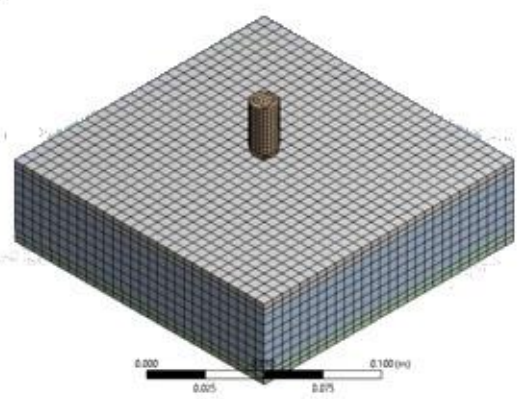

Fig. 2. Meshing of Sandwich Structure 
Table 1. Properties of Materials: Glass Epoxy (GE) and Jute Epoxy (JE)

\begin{tabular}{|c|c|c|}
\hline Parameter & GE & JE \\
\hline \multicolumn{3}{|c|}{ Youngs Modulus (MPa) } \\
\hline $\mathbf{E}_{11}=\mathbf{E}_{22}$ & 36,300 & 4,500 \\
\hline $\mathbf{E}_{33}$ & 36,100 & 3,200 \\
\hline \multicolumn{3}{|c|}{ Shear Modulus (MPa) } \\
\hline $\mathbf{G}_{12}$ & 44,700 & 1,450 \\
\hline $\mathbf{G}_{23}=\mathbf{G}_{13}$ & 46,800 & 1,630 \\
\hline \multicolumn{3}{|l|}{ Poisson's ratio } \\
\hline$\mu_{12}$ & 0.173 & 0.24 \\
\hline$\mu_{13}=\mu_{23}$ & 0.279 & 0.27 \\
\hline Density $\left(\mathrm{kg} / \mathrm{m}^{3}\right)$ & 1,750 & 1,165 \\
\hline \multicolumn{3}{|c|}{ Tensile strength (MPa) } \\
\hline$X_{T}=Y_{T}$ & 330 & 104 \\
\hline $\mathbf{Z}_{\mathrm{T}}$ & 35 & 11 \\
\hline \multicolumn{3}{|c|}{ Shear strength (MPa) } \\
\hline $\mathbf{S}_{12}=\mathbf{S}_{13}=\mathbf{S}_{23}$ & 35 & 23 \\
\hline \multicolumn{3}{|c|}{ Compressive strength (MPa) } \\
\hline $\mathbf{X}_{\mathbf{C}}=\mathbf{Y}_{\mathbf{C}}$ & 320 & 95 \\
\hline $\mathbf{Z}_{\mathbf{C}}$ & 500 & 102 \\
\hline
\end{tabular}

Table 2 gives the material property of hemispherical tup (structural steel) and core (natural rubber).

Table 2. Material Properties of Structural Steel and Rubber

\begin{tabular}{|l|c|c|c|c|c|}
\hline & $\begin{array}{c}\text { Density } \\
\left(\mathbf{k g} / \mathbf{m}^{\mathbf{3}}\right)\end{array}$ & $\begin{array}{c}\text { Modulus of } \\
\text { Elasticity E } \\
(\mathbf{M P a})\end{array}$ & $\begin{array}{c}\text { Poisson's } \\
\text { Ratio }\end{array}$ & $\begin{array}{c}\text { Bulk } \\
\text { Modulus } \\
(\mathbf{M P a})\end{array}$ & $\begin{array}{c}\text { Shear Modulus } \\
\text { (MPa) }\end{array}$ \\
\hline $\begin{array}{l}\text { Structural } \\
\text { Steel }\end{array}$ & 7,850 & $2,00,000$ & 0.3 & $1,66,600$ & $76.9 \times 10^{9}$ \\
\hline Rubber & 1,000 & $1,00,000$ & 0.5 & $1,09,000$ & $300 \times 10^{3}$ \\
\hline
\end{tabular}

\section{Results and Discussion}

Table 3 summarizes the results pertaining to impact analysis of sandwich composites with Jute Epoxy (top face sheet)-Rubber (Core) -Jute Epoxy (bottom face sheet)(JE-R-JE) and Glass Epoxy (top face sheet)-Rubber (Core) -Glass Epoxy (bottom face sheet)(GE-R-GE)

Table 3. Summary of Results

\begin{tabular}{|c|c|c|l|l|l|}
\hline $\begin{array}{c}\text { Sandwich } \\
\text { Structure } \\
\text { Specification }\end{array}$ & $\begin{array}{c}\text { Total } \\
\text { Energy } \\
(\mathbf{m J})\end{array}$ & $\begin{array}{c}\text { Contact } \\
\text { Force } \\
(\mathbf{N})\end{array}$ & $\begin{array}{c}\text { Deformatio } \\
\mathbf{n}(\mathbf{m m})\end{array}$ & $\begin{array}{c}\text { von Mises } \\
\text { Strain }\end{array}$ & $\begin{array}{c}\text { von Mises } \\
\text { Stress } \\
(\mathbf{M P a})\end{array}$ \\
\hline JE-R-JE & $7,462.3$ & 184.41 & 13.206 & 0.415 & 2.636 \\
\hline GE-R-GE & $6,258.3$ & 419.33 & 8.3085 & 0.101 & 17.73 \\
\hline
\end{tabular}




\subsection{Contact Force}

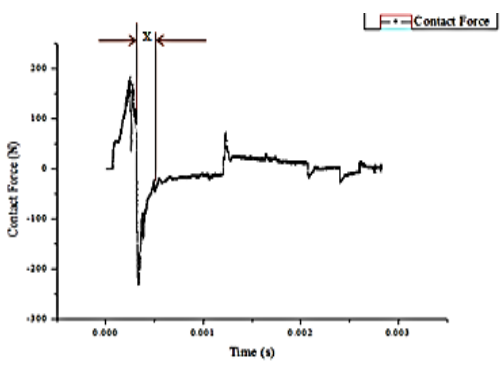

Fig. 3(a). Variation of contact force against

tine for JE-R-JE sandwich

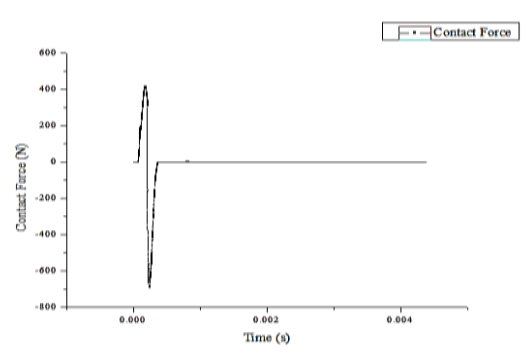

Fig. 3(b). Variation of contact force against tine for GE-R-GE sandwich

Variation of Contact force against time for JE-R-JE and GE-R-GE sandwich is shown in fig $3 \mathrm{a}$ and fig $3 \mathrm{~b}$ respectively. The duration for which the impactor is in contact with sandwich is studied from the graph. Due to different types of fibers used in face sheet, a distinct period of contact with the impactor could be observed. Till the point of initiation of damage or peak load, the variation of force with time is linear. The point where the failure is just initiated on the graph is referred to as the maximum load carrying ability. Siowet al. [16] called it the incipient point of damage which is usually a matrix failure. The extent of damage is very little or no visible damage. Due to this there is a drop in the magnitude of force showing reduction in stiffness of material. The complete failure occurs at the second highest peak where the damage is due to fiber fracture, breakage or delamination and it is visible. This was described as classical mode of failure in composites by Banks et al. [17]. Penetration and perforation damages are the results of combination of such failures. The fig 3(a) shows contact force v/s time curve for jute epoxy skin and rubber core sandwich composite. The max value of force at contact is $184.41 \mathrm{~N}$ at $0.000248 \mathrm{~s}$ and $\mathrm{min}$ is -230.81 $\mathrm{N}$ at $0.00033256 \mathrm{~s}$. For normal components of force and velocity, the Hertzian theory of impact is used where it is assumed that sticking and slipping regions are comprised at the contact area. At the beginning of impact, sliding could be generally observed. In order to reduce this, an opposing frictional force will be established. Sliding will allow rolling to occur if the impact velocity becomes zero which further makes frictional force to become zero. The impact will end once rolling is established.

Forces reverse its direction during impact loading which could be seen from the fig $3 \mathrm{a}$ and fig $3 \mathrm{~b}$. This is agreement with the continuum model established by Maw et al [18]. Full sliding may begin at some point toward the end of impact. At some point during the impact, coincident points on some central portion of the contact zone begin to stick together, while coincident points on the outer annulus of the contact zone may still have some relative slipping. The tangential force leaves the limiting friction envelope and reverses direction. Reverse sliding of the coincident points occurs toward the end of impact, with the tangential force equal to the negative limiting friction value, and persists until contact is lost.

' $\mathrm{X}$ ' in the graph shows the time taken by the sandwich structure to stop the tup. Fig 3(b) shows contact force v/s time curve for glass epoxy skin and rubber core sandwich composite. The max value of force at contact is $419.33 \mathrm{~N}$ and $\min$ is at $-691.05 \mathrm{~N}$. The descending part of unloading is due to continuous loading beyond the peak point where there is a continuous progression of damage to the plate and thus reduction in the contact 
force. Therefore the major mode of failure for this impact loading scenario is due bending stress.

\subsection{Total Energy}

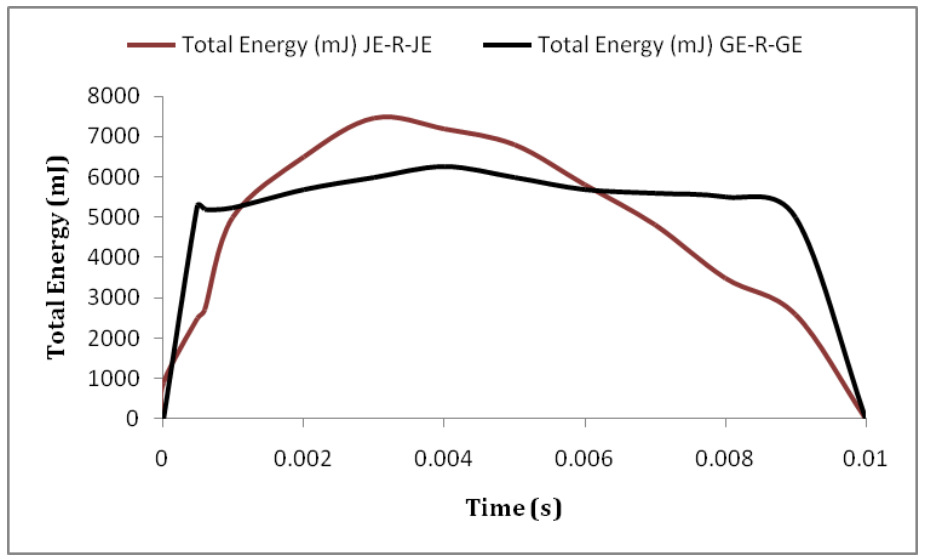

Fig. 4. Comparison of variation of total energy against time for JE-R-JE and GE-R-GE

Fig 4 shows the total energy v/s time graph for JE-R-JE and GE-R-GE. The total energy for JE-R-JE and GE-R-GE is maximum at $7462.3 \mathrm{~mJ}$ and $6258.3 \mathrm{~mJ}$ respectively. The energy absorbed increases gradually over a period of time and then attains zero at the end of impact event.

In case of normal impact loading, the plate gets displaced by the impact of the tup and velocity is constant which refers to the unchanging rate of displacement of an object in a certain period of time due to which the energy absorbed varies linearly. Depending on the variation of velocity of tup after coming in contact with the plate, the energy absorbed varies.

Energy absorption with time increases gradually. When the energy absorbed by the sandwich is small, the impactor bounces back as well as the damage area is also small. This indicates that the impact force can be reduced by increasing the impact time. Elastic deformation and failure mechanisms absorb the energy transferred from object to sandwich. In the graph, the region of linear profile represents the energy absorbed by elastic deformation and anything beyond this point by failure mechanisms. 


\subsection{Total Deformation}

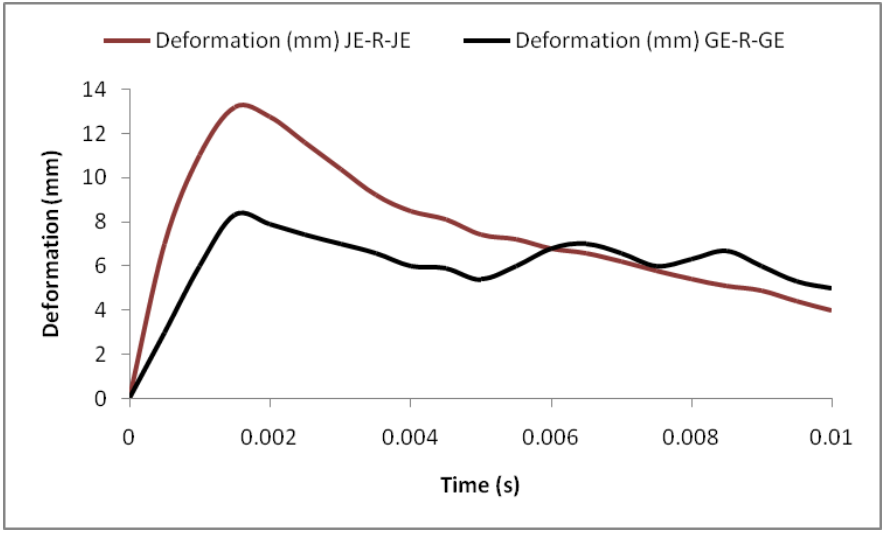

Fig. 5. Comparison of Deformation v/s Time for JE-R-JE and GE-R-GE

Fig 5 shows the deformation v/s time graph for JE-R-JE and GE-R-GE. Due to the impact at the velocity $20 \mathrm{~m} / \mathrm{s}$, JE-R-JE sandwich gets deformed to maximum extent of $13.206 \mathrm{~mm}$ on the top skin and GE-R-GE sandwich gets deformed by $8.3085 \mathrm{~mm}$ at the centre of the top skin and minimum deformation at the edges as the four side faces of sandwich are constrained. The maximum deflections of sandwich composite occur when the impact force becomes equal to zero. During the impact event, the travelling of the impacted surface is indicated by the displacement. Since, drop height of the tup is same in both cases, the amount of energy it delivered on the sandwich will be same [20]. The amount of energy dissipated by the sandwich is a function of the load and displacement of each sandwich, which means that the sandwich with the highest load resistance had the least displacement.

\subsection{Equivalent Elastic Strain and Stress}
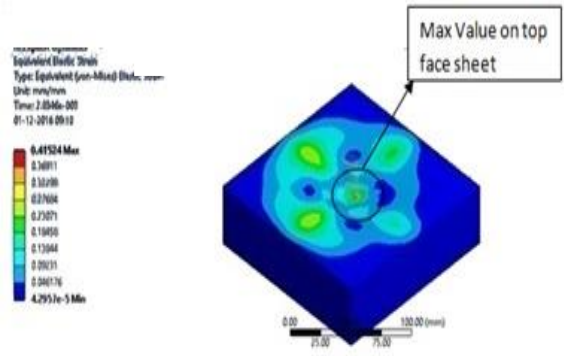

Fig. 6(a). Equivalent elastic strain: JE-R-JE

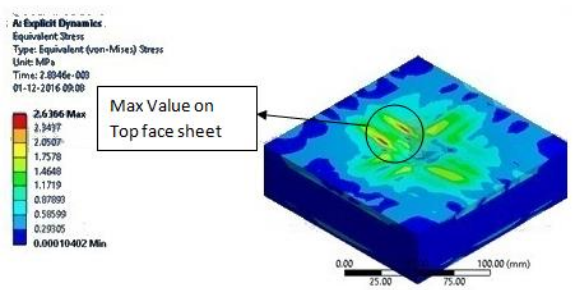

Fig. 6(b). Equivalent elastic stress: JE-

R-JE 


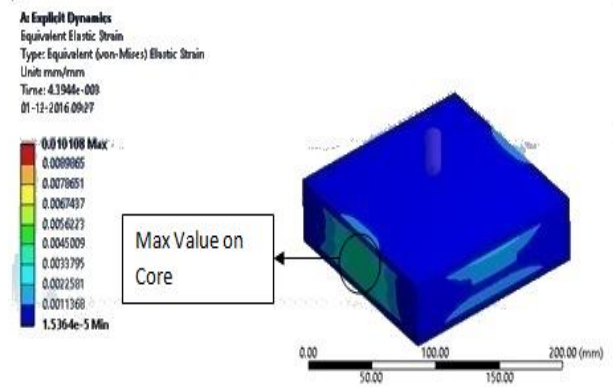

Fig 6(c). Equivalent elastic strain: GE-R-GE

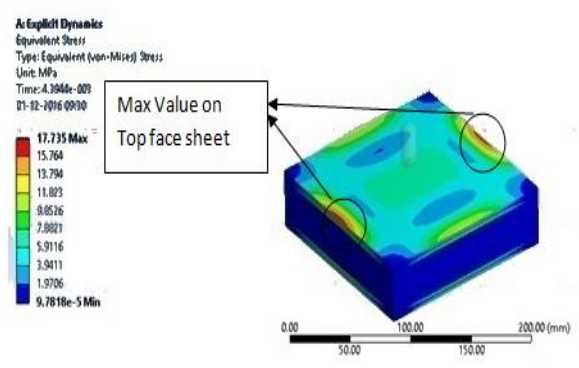

Fig 6(d). Equivalent elastic stress: GER-GE

Fig 6 (a-d) shows the sandwich is subjected to stress and strain due to the impact by the tup at the low velocity of $20 \mathrm{~m} / \mathrm{s}$. The equivalent elastic strain/von Mises strain obtained in case of JE-R-JE and GE -R-GE are 0.415 on top face sheet and 0.101 on core respectively. At the same time the von Mises stress obtained in case of JE-R-JE and GE-R-GE are 2.636 $\mathrm{MPa}$ and $17.73 \mathrm{MPa}$ on top face sheet respectively. It can be found that the von Mises strain in case of JE-R-JE is more when compared with GE-R-GE which is due to its maximum deforming ability thereby absorbing more energy. Also the stress developed in JE-R-JE sandwich composite is less that of developed in GE-R-GE sandwich composite.

\section{Conclusions}

Low velocity impact behavior of two different sandwich composites (JE-R-JE and GE-RGE) are investigated by using FE analysis. Some of the conclusions obtained from this study are as follows:

- Contact Force: The contact force developed in JE-R-JE sandwich is 2.3 times less when compared with GE-R-GE sandwich which shows that jute is less brittle than glass fiber.

- Total Energy: JE-R-JE sandwich absorbs 1.2 times more energy than GE-R-GE sandwich under low velocity normal impact loading. This exhibits the ability of JE-R-JE sandwich to absorb impact loading in low velocity regime.

- Deformation: The amount of energy dissipated by the sandwich is a function of the load and displacement of each sandwich, which means that the sandwich with the highest load resistance had the least displacement. The deformation of JE-R-JE sandwich under low velocity impact is $13.206 \mathrm{~mm}$ which is approximately 1.6 times more than that of GE-R-GE sandwich. This means that GE-R-GE sandwich has highest load resistance compared to JE-R-JE sandwich.

- Equivalent elastic strain and stress: von Mises strain in case of JE-R-JE is more (approximately 4.1 times) when compared with GE-R-GE which is due to its maximum deforming ability thereby absorbing more energy. Also the stress developed in JE-R-JE sandwich is less (approximately 6.7 times) that of developed in GE-R-GE sandwich.

The consequences of this examination shows that for low velocity impact application jute-epoxy has better impact resistance properties than glass epoxy making them suitable for structural/ semi structural applications. The use of natural rubber as core material enhances the energy absorbing ability of the sandwich structure. In spite of 
the fact that the composites have some benefits and disadvantages, the blend of the helpful properties of two unique materials, faster handling time, and lower producing cost make them as a flexible material in the field of designing and innovation.

\section{References}

1. Dinh Chi Pham and Sridhar Narayanaswamy, "An Optimization Tool for Impact Analysis of Composite Structures", Proceedia Eng., 75, pp3 - 8 (2014).

2. M. Sadighi and M. Saadati, "Unequal faces effect on fracture of composite sandwich beam with flexible core," Appl. Compos. Mater, 17(2), pp. 111-120 (2010).

3. Vinson, J.R. "The Behavior of Sandwich Structures of Isotropic and Composite Materials", Technomic Publishing, Lancaster, PA (1999)

4. Aktay, L., Johnson, A.F. and Holzapfel, M. 'Prediction of impact damage on sandwich composite panels', Comput. Mater.Sci., 32 (3-4), pp.252-260 (2005).

5. Brenda, L.B., Carlos, S., Sonia, S., Enrique, B. and Carlos, N. 'Modelling of composites and sandwich structures with honeycomb core subjected to high-velocity impact', Compos. Struct., 92(9), pp.2090-2096 (2010).

6. HooFatt, M.S. and Sirivolu, D. 'A wave propagation model for the high velocity impact response of a composite sandwich panel', Int. J. Impact Eng, 37(2), pp.117130 (2010).

7. Morye, S.S., Hine, P.J., Duckett, R.A., Carr, D.J. and Ward, I.M. 'Modelling of the energy absorption by polymer composites upon ballistic impact', Compos. Sci. Technol, 60(14), pp.2631-2642 (2000).

8. Edgren, F., Soutis, C. and Asp, L.E. 'Damage tolerance analysis of NCF composites and sandwich panels', Comp. Sci. Tech., 68 (13), pp.2635-2645, (2008)

9. Karger, L., Baaran, J. and Tessmer, J. 'Rapid simulation of impacts on composite sandwich panels inducing barely visible damage', Compos. Struct, 79 (4), pp.527-534 (2007).

10. Meo, M., Vignjevic, R. and Marengo, G. 'The response of honeycomb sandwich panels under low-velocity impact loading', Int. J. Mech. Sci., 47 (9), pp.1301-1325 (2005)

11. Balasubramani V, Rajendra Boopathy S and Vasudevan R, "Numerical Analysis of Low Velocity Impact on Laminated Composite Plates", Procedia Eng., 64, pp.10891098 (2013)

12. Stuart M Lee, "Handbook of composite reinforcement", Wiley publications, (1992).

13. A. Mir, C. Aribi, B. Bezzazi, "Study of the Green Composite Jute/Epoxy", Int. J. Chem., Mol., Nuc., Mat. Met. Engg., 8 (2), (2014).

14. D Tabor, "The bulk modulus of rubber", Journal of Polymer, 35(13),pp. 2759-2763 (1994)

15. M. R. Hossain , M. A. Islam, A. V. Vuurea, and I. Verpoest, "Effect of Fiber Orientation on the Tensile Properties of Jute Epoxy Laminated Composite", J. Sci. Res. 5 (1), pp. 43-54 (2013).

16. Siow YP, Shim VPW. "An experimental study of low velocity impact damage in woven fibre composites" J.Comp. Mat., 32, (1998)

17. Banks WM, David-West OS, Alexander NV, Nash DH. Energy absorption and bending stiffness in CFRP laminates: The effect of 451 plies. Thin-walled Structures, 46, (2008)

18. Maw, N., Barber, J. R., and Fawcett, J. N., "The Oblique Impact of Elastic Spheres," Wear, 381, pp. 101-114, (1976)

19. Philip P. Garland and Robert J. Rogers, "An Experimental Study of Contact Forces during Oblique Elastic Impact” J. Appl. Mech., 76, (2009) 
20. Alex M. Remennikov, Sih Ying Kong and Brian Uy, M.ASCE, "Response of Foamand Concrete-Filled Square Steel Tubes under Low-Velocity Impact Loading" J. Perform. Constr. Fac, 373-381, (2011). 